\title{
Deep Brain Stimulator insertion: what should we know as anaesthetists?
}

\author{
G De Zylva ${ }^{1^{*}}$, W Ali $^{1}, \mathrm{~K}$ Ashkan ${ }^{2}$ \\ Consultant Anaesthetist ${ }^{1}$, Professor of Neurosurgery ${ }^{2}$, King's College Hospital, London, \\ United Kingdom
}

Corresponding author:gowri.dezylva@ nhs.net

Deep brain stimulation is the surgical treatment modality of choice for otherwise treatment resistant and affective disorders such as dystonia, tremor and Parkinson's disease. Furthermore, DBS is now being used or investigated in the management of other conditions such as chronic pain, depression, obsessive compulsive disorder, Tourette syndrome, obesity, epilepsy and Alzheimer disease.

The exact mechanism of action of DBS is not completely understood. The primary target sites vary according to patient's symptoms. The various target sites are subthalamic nucleus, globus pallidus, pars internal and ventralis intermedius nucleus of thalamus.

The surgical procedure involves insertion of electrodes into the target area of the brain through a burr hole. This is achieved through a combination of anatomical/imaging techniques (MRI and $\mathrm{CT}$ ) and neurophysiological verification such as macro stimulation or micro-electrode recording. Once confirmed the electrode is connected via the cable to the pulse generator.

The anaesthetic management describes the common and special consideration for awake DBS insertion and insertion under general anaesthesia and postoperative management of these patients.

In our institute DBS has been practiced for well over a decade, allowing our multi-disciplinary team to build a large experience spanning both the main and experimental indications and across both the paediatric and adult age groups. The scope of this article is to understand the surgical steps and describe the practical aspect of conducting anaesthesia for patients undergoing DBS including challenges of awake surgery and post-operative care.

Keywords: Deep brain stimulation, Parkinson's disease, affective disorders, anaesthesia

\section{Introduction}

Traditionally, ablative procedures such as thalamotomy and pallidotomy were used to treat a range of neurological conditions such as Parkinson's disease (PD) and tremor. These lesioning procedures were, however, irreversible and associated with several permanent side effects. $^{1}$

Modern Deep brain stimulation was first described in 1987 as an alternative to ablative procedure to reduce the symptoms of Parkinson's disease., The option to deliver stimulation safely bilaterally along with the ability to titrate the stimulation to the needs of the patient and the reversibility of the technique, has made deep brain stimulation the surgical treatment modality of choice for many movement disorders such as dystonia, tremor and Parkinson disease. Furthermore, DBS is now being used or investigated in the management of other conditions such as chronic pain, depression, obsessive compulsive disorder, Tourette syndrome, obesity, epilepsy and Alzheimer disease . ${ }^{4,5,6}$ 


\section{Mechanism of action}

The exact mechanism of deep brain stimulation is not completely understood and may differ depending on the site of stimulation and the condition being treated. The primary target sites vary with patients and symptoms and include the subthalamic nuclei (STN), globus pallidus pars interna (GPi) and the ventralis intermedius nucleus of thalamus (Vim). ${ }^{7}$ (Figure 1).

(a) Stimulation of STN- This is the most widely used target for PD and has been proven to be effective in treating the tremor, bradykinesia and rigidity. Furthermore, many patients will also be able to reduce their medications significantly which will improve side effects such as dyskinesia's. ${ }^{8}$ There are now several randomized trials confirming the benefits of STN DBS in improving patients quality of life compared to the best medical therapy. ${ }^{9}$ Of interest, STN DBS may decrease glutamate production from the STN which has been hypothesized to confer a neuro protective effect. $^{10,11,12}$

(b) Stimulation of the GPi - In the context of PD, GPi DBS is particularly effective against dyskinesia. Its widest application, however, is to treat dystonia where it may modulate neuronal plasticity. ${ }^{13}$

(c) Stimulation of the Vim (Thalamus) - Highly effective for the treatment of essential tremor and also tremor dominant PD.

\section{Surgical technique}

The DBS system consists of three components: the electrode, the cable, and the battery which generates pulse. The surgical procedure involves insertion of the electrode in to the target area of the brain through the burr hole, which is then connected via the cable to the programmable pulse generator. The latter is usually placed just below the left clavicle (to avoid car seat belt pressing the battery) or in the abdomen. Insertion of the electrode and the connection to the implanted battery may occur during the same operative session or a few days later depending on the nature of the condition being treated and the surgical technique. (Figure 2)

Placement of electrodes requires maximum accuracy, given the very small size of the target nuclei (a few millimetres in diameter). This is achieved through a combination of anatomical/ imaging techniques and neuro-physiological verification such as macro stimulation or microelectrode recording (MER). The anaesthetic requirement of this stage depends on the type of disease, tradition and institutional preference. The surgery may be done under local anaesthesia, conscious sedation or general anaesthesia. Although there is a wide variation in techniques, in most institutions, the initial step is the placement of a rigid stereotactic head frame to the patients skull (Figure 3) followed by a MRI scan to visualize the brain structures and establish reference to external frame landmarks to obtain coordinates for accurate insertion of the electrode into the target area of the stimulation. Next, burr hole is performed and the electrode is placed through the burr hole by the surgeon. In most units, once the electrode reaches the anatomical target, neuro-physiological evaluation is performed to accurately define the most clinically effective point within the target volume. This may involve micro-electrode recording to look for signature activity of brain nuclei or macro stimulation in awake patients to observe improvement of symptoms and lack of any side effects.

The next step involves connecting the electrode to the cable which is tunnelled from the scalp, subcutaneously across the neck to an infraclavicular area or to the abdomen, where it is connected to the pulse generating battery. This stage is commonly performed under general anaesthesia. 


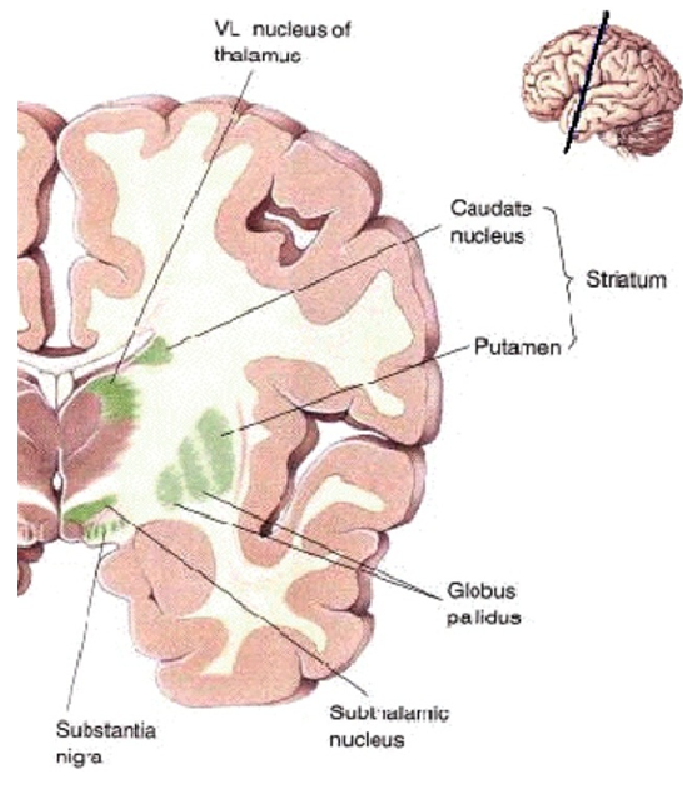

Figure 1: Deep Brain Nuclei

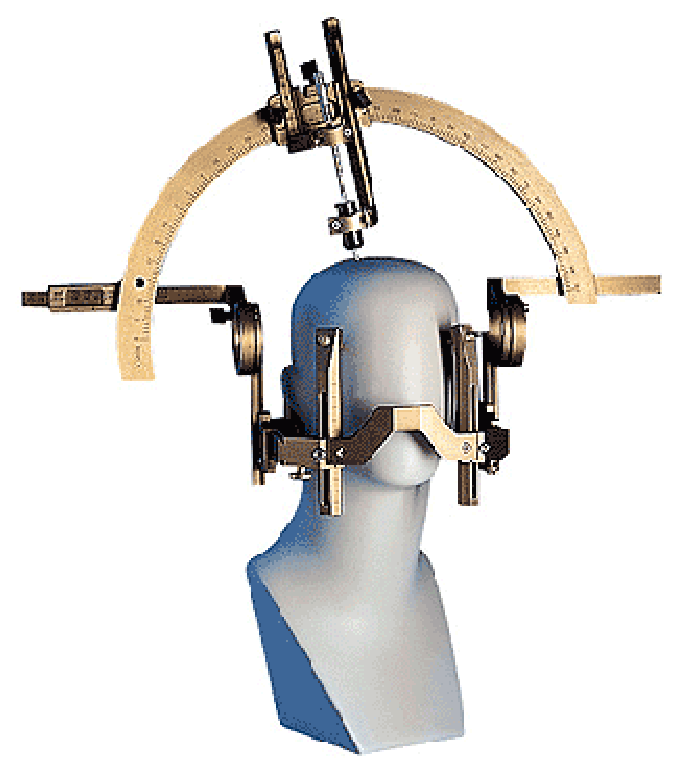

Figure 3: Rigid frame

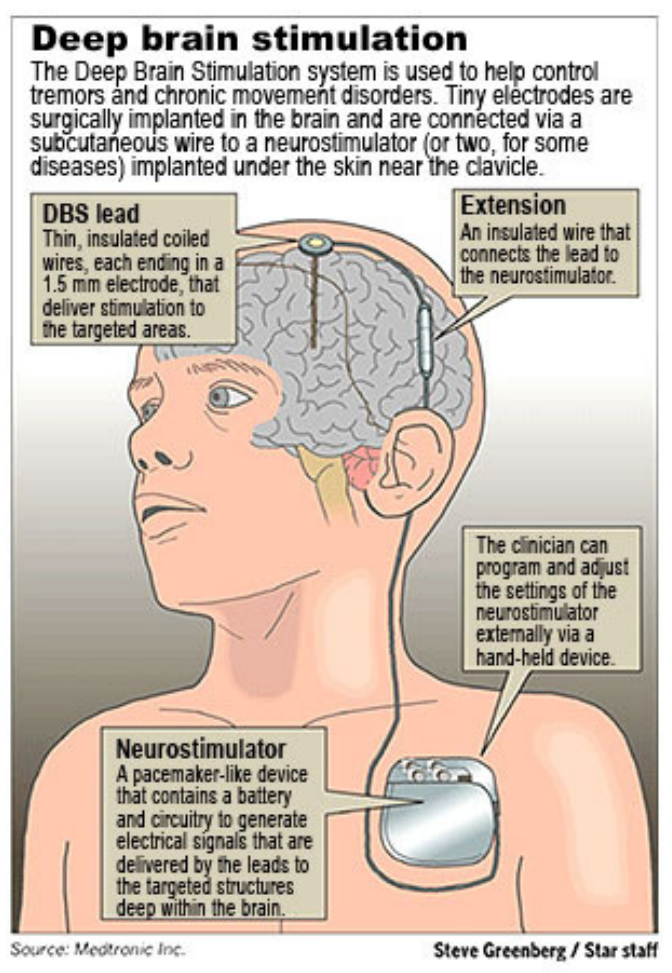

Figure 2: Deep Brain Stimulator and the battery 
MERs and Macro stimulation testing and different anaesthetic agents

\begin{tabular}{|c|c|}
\hline Anaesthetic agents & GPi \\
\hline $\begin{array}{l}\text { Propofol in dystonia } \\
\text { group } 14\end{array}$ & $\begin{array}{l}\text { Firing rates substantially } \\
\text { decreased with long } \\
\text { pause }\end{array}$ \\
\hline $\begin{array}{l}\text { Propofol in Parkinson's } \\
\text { group }\end{array}$ & No difference \\
\hline $\begin{array}{l}\text { Desflurane in dystonia } \\
\text { group }^{15}\end{array}$ & $\begin{array}{l}\text { No difference same as } \\
\text { awake group }\end{array}$ \\
\hline $\begin{array}{l}\text { Desflurane in } \\
\text { Parkinson's group }{ }^{15}\end{array}$ & $\begin{array}{l}\text { Significant decrease in } \\
\text { firing rate }\end{array}$ \\
\hline Awake group ${ }^{15}$ & $\begin{array}{l}\text { No difference same as } \\
\text { anaesthetized group }\end{array}$ \\
\hline
\end{tabular}

The difference in the anaesthetic effect on these target nuclei may be due to the amount of their GABA input. The GPi neurons have greater GABA input compared with the STN neurons and, therefore, are suppressed by most anaesthetic agents. ${ }^{16}$

\section{Anaesthetic management}

\section{Preoperative evaluation and preparation}

DBS patients are managed by a multidisciplinary team consisting of neurologists, neurosurgeons, neurophysiologist, neuropsychologist, psychiatrist, anaesthesiologist and clinical nurse specialist. Correct patient selection is vital for the successful outcome.

\section{Anaesthetic consideration in awake DBS insertion}

Apart from the routine evaluation the specific considerations are:

1. Good psychological preparation.

2. Proper airway assessment: Patients with obstructive sleep apnoea the CPAP mask may need to be placed before placing the stereotactic frame. ${ }^{17}$ (Figure 3) This frame could cause potential airway difficulty in emergency.

3. Normal blood pressure. Anxiety during the procedure can increase the blood pressure and pose risk of intra cerebral bleed.

4. Pain management in chronic pain patients.

5. "Drug - off" states to facilitate intraoperative mapping and clinical testing may worsen the patient's symptoms and possess challenge to perioperative care. $^{17}$

6. Patients should be informed of different locations of care- operating room

(IV cannulation and placement of stereotactic frame on the skull) - MRI (for localizing the target) - back to operating room (long procedure and frequent macro stimulation testing, sitting position and need to empty the bladder before starting the procedure) - Post-operative imaging to confirm the location of electrode and back to operating room for connection to the battery under general anaesthesia if the whole procedure is to take place on the same day.

The placement of the stereotactic frame and the burr hole can be performed by infiltration of local anaesthetic agent to the site of the pins and the site of burr hole or by supraorbital and occipital nerve blocks. Although nerve blocks have shown to be less painful than local infiltration, there is no difference in pain at the time of pin placement or during the surgery. ${ }^{18}$

Standard anaesthetic monitoring needs to be performed. It may be technically difficult in movement disorder patients. Supplementary oxygen may be administered through the nasal prongs. Awake patients may be more comfortable without a urinary catheter. Therefore meticulous fluid management is necessary to avoid hypovolemia and at the same time to avoid a full bladder. Before starting the procedure it is very important to make sure that patient is optimally positioned in a maximal comfortable position to 
get the patient cooperation during the surgery. Patient should be warned of sudden onset of hotness (hyperthermia) due to stimulation of hypothalamus.

\section{Anaesthetic considerations for DBS insertion under general anaesthesia}

In paediatric patients, those with dystonia and patients intolerant of awake surgery, for example due to claustrophobia, DBS is usually performed under general anaesthesia. In some units, general anaesthesia may be preferred for all cases. The special considerations in these cases are:

1. Co morbid medical conditions, elderly and paediatric patients

2. Polypharmacy and altered pharmacokinetics and dynamics

3. Potential drug interactions.

4. Airway management: avoid reinforced ET tube causing interference and possible burn in MRI. LMA or RAE tube could be used to secure the airway. Increase risk of regurgitation and aspiration needs to be considered in patients with Parkinson's disease.

5. Transporting anaesthetised patient for different locations: Transport monitoring, emergency drugs and safety issues in MRI and CT.

6. Possibility of awareness: anaesthetic may interfere the microelectrode recording. Therefore the depth of anaesthesia may need to be reduced to obtain good recording.

It is important to choose the appropriate inducing and maintaining agents for different disorders to achieve optimal microelectrode recording. In our institute we use propofol for induction and use oxygen /air/ sevoflurane, remifentanil infusion for maintenance. Apart from routine anaesthetic monitoring, direct arterial blood pressure measurement may be considered. There is the concern that AC current may also interfere with microelectrode recording and all equipment using AC current may need to be switched off temporarily.

The other common considerations for awake and anaesthetized patients are antibiotic prophylaxis and strict aseptic procedure to avoid infection in deep brain structures. The coagulation profile should be within normal range to avoid bleeding. The key to the frame needs to be kept preferably with the anaesthetic team in case emergency airway access is needed. Tunnelling of the cable and battery placement is routinely done under general anaesthesia, requiring the airway to be secured with endotracheal tube, because access to the airway is restricted during tunnelling.

\section{Postoperative management}

Apart from routine monitoring, an intensive pain management program should be considered in specific patient groups, particularly the paediatric patients. In our institution we manage such patients with regular paracetamol and patient controlled or nurse controlled analgesia. To avoid infection in deep brain structures antibiotics should be considered according to local hospital policy.

Reduction or absence of anti-Parkinson medication can cause respiratory insufficiency postoperatively. Anti- Parkinson drugs can cause orthostatic hypotension which may be aggravated by the vasodilating effects of the anaesthetic agents, perioperative hypovolemia and autonomic dysfunction. There are reported cases of air embolism in seated position. ${ }^{19}$ Sudden onset of cough in an awake patient could be due to air embolism.

\section{DBS patient for battery change}

There are now a range of batteries available, both fixed life and rechargeable. Fixed life batteries 
tend to be most widely used in adults whilst rechargeable ones are preferred in the paediatric population. ${ }^{20}$ The fixed life battery usually lasts about 3-5 years. Anaesthesia for battery change is a relatively simple procedure. It can be done under general anaesthesia with LMA and patient breathing spontaneously.

\section{DBS patients for other surgery}

The specific consideration is the use of unipolar diathermy which is contra-indicated. Antibiotic prophylaxis is usually recommended by most DBS specialists. It should be noted that, most patients are very much dependent on their DBS. If the battery needs to be switched off during the surgical procedure, it is best to switch it off just before inducing anaesthesia and turn it back on just before waking the patient.

\section{References}

1. Lozano AM, Lang AE, Pallidotomy for Parkinson's disease. Arch Neurol 2005,62: 137781.

2. Benabid AL, Pollak P, Gervason C, et al. Long term suppression of tremor by chronic electrical stimulation of the ventral intermediate thalamic nucleus.Lancet1991;337:403-6 http://dx.doi.org/10.1016/0140-6736(91)91175-T

3. Benabid AL, Pollak P, Louveau A, et al. Combined (thalamotomy and stimulation) stereotactic surgery of the VIM thalamic nucleus for bilateral Parkinson disease. ApplNeurophysiol1987;50:344-6 http://dx.doi.org/10.1159/000100803

4. Pereira EA, Green AL, Nandi D. Deep brain stimulation of the subthalamic nucleus for the treatment of Parkinson's disease. Lancet Neurol 2009;8:67-81

http://dx.doi.org/10.1016/S1474-4422(08)70291-6

5. Halpern $\mathrm{C}$, Hurtig H, Jaggi $\mathrm{J}$ et al. Deep brain stimulation in neurologic disorders. Parkinsonism Relat Disord 2007;13:1-16 http://dx.doi.org/10.1016/j.parkreldis.2006.03.001 PMid:17141550

6. Marangell LB, Martinez M, Jurdi RA, Zboyon H. Neurostimulation therapies in depression: a review of a new modalities. Acta psychiatr scand 2007; 116:174-81. http://dx.doi.org/10.1111/j.1600-47.2007.01033.x PMid:17655558

7. Johnson MD, Micinovic S, Mcintyre C C, Vitek J L. Mechanism and targets of deep brain stimulation in movement disorders. Neurotherapeutic2008;5:294-308. http://dx.doi.org/10.1016/j.nurt.2008.01.010 PMid:18394571 PMCid:PMC2517242

8. Krack $P$ et al. Five year follow up of bilateral stimulation of the subthalamic nucleus in advanced Parkinson disease. $\mathrm{N}$ Eng $\mathrm{J}$ ed. 2003Nov13;349(20):1925-24

9. Williams A et al. Deep brain stimulation plus best medical therapy versus best medical therapy alone for advanced Parkinson's Disease (PDSURG Trial): A randomized open label trial. Lancet neurol.2010Jun;9,581-591.

http://dx.doi.org/10.1016/S1474-4422(10)700934

10. Wallace B A et all. Survival of midbrain dopaminergic cells after lesion or deep brain stimulation of the subthalamic nucleus in MPTPtreated Monkeys.Brain 2007 Aug;130:2129-45 http://dx.doi.org/10.1093/brain/awm137

PMid:17584773

11. Benazzauz A, Hallett M. Mechanism of action of deep brain stimulation. Neurology 2000;55:13-6

12. Wamke PC.STN stimulation and neuroprotection in parkinson's disease: when beautiful theories meet ugly facts. J Neurol Neurosurg Psychiatr 2005;76:1186-7

http://dx.doi.org/10.1136/jnnp.2004.061481 PMid:16107346 PMCid:PMC1739795

13. Tisch $\mathrm{S}$, et al. Pallidal stimulation modifies aftereffects of paired associative stimulation on motor cortex excitability in primary generalised dystonia. EXP Neurol.2007Jul;206(1):80-5. http://dx.doi.org/10.1016/j.expneurol.2007.03.027 PMid:17498697

14. Hutchison WD, Long AE, Dostrovsky JO, Lozano AM, Pallidal neuronal activity: implications for models of dystonia. Ann Neurol 2003;53:480-8 http://dx.doi.org/10.1002/ana.10474

PMid:12666115

15. Sanghera MK,Grossman RG, Kalhorn CG, Hamilton WS, Ondo WG, Jankovic J. Basal ganglia neuronal discharge in primary and secondary dystonia in patients undergoing pallidectomy. Neurosurgery 2003;52:1358-73 http://dx.doi.org/10.1227/01.NEU.0000064805.91 249.F5

PMid:12762881

16. Benarroch EE. Subthalamic nucleus and its connections: anatomic substrate for the network effects of deep brain stimulation. Neurology 
2008;70:1991-5

http://dx.doi.org/10.1212/01.wnl.0000313022.393

29.65

PMid:18490619

17. Lukshmi V, Michelle L, Pirjo M. Anaesthetic Management of patients undergoing Deep Brain Stimulator insertion. Anaesthesia and Analgesia. April 2010;110(4): 1138-1145.

18. Watson R, Leslie K. Nerve blocks versus subcutaneous infiltration for stereotactic frame placement. Anaesth Analg 2001;92:424-7. http://dx.doi.org/10.1213/00000539-20010200000028

19. Hooper AK, Okun MS, Foote KD, Haq IU, Fernandez HH, Hegland D, Robicsek SA. Venous air embolism in deep brain stimulation. Steriotact funct Neurosurg 2008;87:25-30 http://dx.doi.org/10.1159/000177625

PMid:19039260

20. Kaminska $M$ et al. Rechargeable deep brain stimulators in the management of pediatric dystonia: well tolerated with a low complication rate. Stereotact funct neurosurg.2012;90(4):233-9 http://dx.doi.org/10.1159/000337768

PMid:22699777 